\title{
La obra poética de Juan Bautista Aguirre y los problemas de su transmisión
}

\author{
Juan Bautista Aguirre and the problems \\ of the transmission of his poetry
}

Estela Castillo Hernández y Ángel José Fernández*

Resumen: Juan Bautista Aguirre, el poeta ecuatoriano que vivió durante el siglo XVIII y que fue expulsado en 1767, ha sido ignorado por la crítica hispanoamericana colonial durante los últimos años. Escribió poesía filosófica y moral, aunque es mejor conocido por su veta humorística, por la que se le ha comparado con Juan del Valle y Caviedes. En este trabajo, ofrecemos un panorama de los problemas de transmisión que ha sufrido su obra poética escrita en español, víctima de lecturas sesgadas, descontextualizadas y prejuiciadas; indicamos, también, los editores que han compilado su obra y las circunstancias bajo las cuales se ha rescatado su poesía.

Palabras clave: Juan Bautista Aguirre, siglo XVIII, poesía hispanoamericana, crítica textual, problemas de transmisión.

Abstract: Juan Bautista Aguirre, the Ecuadorian poet who lived during the eighteenth century and who was exiled in 1767 , has been ignored by the literary criticism in recent years. He wrote philosophical and moral poetry, although he is best known for his humorous vein, which has been compared to Juan del Valle y Caviedes. In this text, we present an overview of the problems of transmission that has suffered his poetry written in Spanish, victim of decontextualized and prejudiced readings; we also show the editors who have compiled his poetry and the circumstances under which his poems has been rescued.

\footnotetext{
Instituto de Investigaciones Lingüístico-Literarias de la Universidad Veracruzana E-mail: estelcastillo@uv.mx / afernandez@uv.mx
} 
Key words: Juan Bautista Aguirre, century XVIII, Spanish-American poetry, textual criticism, the problems of transmission

Recibido: 15 de octubre de 2016

Evaluado: 14 de diciembre de 2016 
El jesuita Juan Bautista Aguirre Carbo nació en el pueblo de Daule, distrito de las Guayas, en las cercanías de Guayaquil, el 11 de abril de 1725. Fueron sus padres el capitán Carlos Aguirre y Ponce de Solís y Teresa Carbo y Cerezo, "ambos nativos de Guayaquil". Se educó en Quito, primero en el Colegio Seminario de San Luis y luego en la Compañía de Jesús, a la que se incorporó el día en que cumplió quince años, en 1740. Según Zaldumbide, hizo profesión de fe el 15 de agosto de 1758, cuando contaba 33 años de edad. Impartió Filosofía y Teología moral en la Universidad de San Gregorio Magno, fue prefecto de la Congregación de San Javier, "y desde 1765 socio consultor del provincial de Quito, padre Manosalvas"2.

Vivió en la actual capital del Ecuador durante tres décadas, y puede decirse que allí compuso todas sus producciones hasta ahora conocidas en verso latino y castellano, con varios registros y temas (escribió poemas de carácter amoroso, así como composiciones religiosas sobre san Ignacio de Loyola, la virgen María y Luzbel, sonetos morales, fábulas, sátiras y polémicas en prosa y verso) $;^{3}$ allí se convirtió en orador sagrado y escribió algunas obras, entre las principales, publicó una carta pastoral, a nombre del obispo Nieto Polo del Águila, en "ocasión del terremoto y desolación de Latacunga" (1757), y varios sermones, como la Oración fúnebre, para las exequias del mencionado obispo de Quito (1760); tradujo del latín obras teológicas, como la "Disputa III de la Física" y "Disputa II de la Ontología o Metafísica"4; y dejó inéditas, además de muchos de sus poemas, piezas de discusión y argumentación teológica ${ }^{5}$.

Al cumplirse en tierras hoy ecuatorianas la pragmática con que Carlos III decretó la expulsión de los jesuitas de los territorios hispánicos, impuesta en agosto de 1767, Aguirre se hallaba "incidentalmente" en Ambato. Se embarcó el 3 de octubre en la fragata Santa Bárbara rumbo a los territorios papales y tras muchas vicisitudes e incidencias sufridas en Panamá -donde murió su provincial, el padre Manosalvas-, tocó Cartagena de Indias, Cuba y Jamaica, hasta arribar a tierra firme europea en el puerto de Cádiz. Llegó a Faenza, "y de ahí pasó a Rávena, como superior del convento de esa ciudad" . En Ferrara sería designado por el padre Ricci rector del colegio y más tarde lo nombró el arzobispo de esa ciudad examinador sinodal. Cuando el papa Clemente XIV extinguió la Compañía de Jesús en 1773, Aguirre fijó su residencia en Roma, donde como muchos otros jesuitas americanos seguramente se secularizó para convertirse en sacerdote y pasar al servicio eclesiástico en la Congregación del Santo Oficio y en la de Propaganda Fide, donde colaboró por espacio de cinco años. De Roma fue trasladado al castillo de San Gregorio, cercano a Tivoli, y de este sitio pasó a dicha ciudad, donde colaboró en su diócesis durante la etapa final de su vida como teólogo con el obispo Julián Mateu Natali y sus sucesores, monseñor Barnaba Chiaramonti -quien en 1820 sería electo papa, con el nombre de Pío VII- y finalmente, colaboró con monseñor Manni, quien le otorgó la cátedra de Teología moral del Colegio Público de Tivoli, hasta que enfermó y murió el 15 de junio de $1786^{7}$.

\footnotetext{
${ }^{1}$ Zaldumbide, 1960: 352.

${ }^{2}$ Ibídem.

${ }^{3}$ Espinosa Pólit ha realizado prolija relación de sus obras en "Establecimiento del texto definitivo de las poesías de Aguirre" (Zaldumbide, 1960: 436-438).

${ }^{4}$ Véase Herrera, 1860: 282-289.

${ }^{5}$ Uriarte, 1925: 58-59.

${ }^{6}$ Zaldumbide, 1960: 355.

${ }^{7}$ Ibíd.: 352-358.
} 
Ahora bien, debemos a la curia de Juan María Gutiérrez, el editor de América poética, la primera transmisión de sus poemas, quien los dio a conocer, para empezar, en su libro Estudios biográficos y críticos sobre algunos poetas sudamericanos anteriores al siglo XIX, publicado en Buenos Aires en $1865^{8}$; más tarde, en la que iba a ser la segunda edición, refundida y aumentada, de la citada América poética (tomo I), obra impresa también en Buenos Aires, un año más tarde, en $1866^{9}$ y después daría las primicias acerca de su vida y su obra en la primera serie de su "Biblioteca de escritores en verso", que publicó en Revista del Río de la Plata, y en la que advirtió que ya en 1865 había hecho "un estudio sobre la persona y escritos del Padre Aguirre", en el que además había recogido "algunas muestras del talento poético de este notable americano" $"$.

José Joaquín de Olmedo le había allanado a Gutiérrez el camino para la localización del primer manuscrito de sus versos, en carta que le remitió desde Lima el 2 de agosto de 1846. Este texto, que se hallaba en poder de José María Dávila, vecino de Guayaquil, tenía la "apariencia de un autógrafo, por las variantes y correcciones que en él se notan y que no pueden provenir sino del autor mismo" ". Gutiérrez agregó: formaba "un volumen in $4^{\circ}$ de 140 folios completos, con este título: Versos castellanos, obras juveniles, misceláneas". Esta colección contenía "copias duplicadas de unos mismos versos, y composiciones a medio hacer, como por ejemplo un «Poema heroico a San Ignacio de Loyola», en silva, que no quiso concluir el autor, según consta de una nota marginal, por «no tener gana ni tiempo»" $"$. Gutiérrez comenta sobre esta nota: "Ambas razones son poderosas y muy en armonía con el carácter franco y despreocupado que el padre Aguirre descubre en sus escritos ligeros"13.

Esta idea, aunque algo extendida, resulta injusta en su apreciación, pues se le achacaban a Aguirre sobre todo obras en verso que pecaban de populares, ligeras, inclusive vulgares, todo lo cual provenía de lo que había afirmado Pablo Herrera en su Ensayo sobre la Historia de la Literatura Ecuatoriana, que Gutiérrez no llegó a conocer en los momentos en que escribía sus Estudios biográficos y críticos, pero que de alguna forma ratificó con lo acabado de citar. Afirmó Herrera que Aguirre tenía "grande reputación como orador y poeta; mas si es verdad que compuso algunos versos regulares, sus discursos se hallan desprovistos de verdadera elocuencia"14; también señalaba que la Oración fúnebre, que dedicó al obispo de Quito, tenía mayor "afectación que naturalidad, más adorno que solidez, más altisonancia que verdad" y que como poeta ostentaba, al igual que los padres Vega, Moscoso, Viescas y Andrade, "una imaginación viva y pintoresca en algunas apologías y composiciones sueltas", impregnadas, algunas, de "gracia y belleza" desprenderse de su propia invención y no de la constatación y lectura de sus obras; este

\footnotetext{
${ }^{8}$ Ibíd.: 387.

${ }^{9}$ Carilla, 1943: 9.

${ }^{10}$ Gutiérrez, 1871: 653.

${ }^{11}$ Zaldumbide, 1960: 387.

${ }^{12}$ Ibídem.

${ }^{13}$ Ibídem.

${ }^{14}$ Herrera, 1860: 99.

${ }^{15}$ Ibíd.: 97.
} 
historiador, además, haría nacer al padre Aguirre en Guayaquil ${ }^{16}$; error que a partir de entonces se copió en muchas otras fuentes ${ }^{17}$.

La recepción de los poemas populares de Aguirre, en particular las "Décimas" satíricas sobre Guayaquil y Quito ${ }^{18}$, así como el fragmento de la silva barroca que arregló sobre la vida de Loyola, entre alguna pieza más, malversaron las opiniones acerca de sus obras serias, muchas de las cuales no fueron impresas por Gutiérrez sino a partir de 1865, como se ha dicho. Juan León Mera, en Ojeada histórico-crítica sobre la poesía ecuatoriana rompió lanzas contra el nacido en Daule, al suponer al poeta como posible atrevido, que había cerrado "los ojos a la luz del buen gusto que se difundía por la península, y no quiso abandonar las doctrinas de la vacilante escuela [es decir la gongorina], sino más bien sostenerlas con el ejemplo"19. Para León Mera éste era un "pecado" imperdonable. El poema sobre el general de la orden le causaba "pena", pues lo creía producto del delirio, en tanto que los ataques levantados en contra de sus vecinos quiteños lo tornaban en poeta vulgar, enviciado e imperfecto ${ }^{20}$. Detrás de tales valoraciones, por una parte, está latente el menosprecio por la poesía gongorina, que data del siglo XVII y que se hizo más violento en la centuria siguiente. Durante el siglo XVIII, las críticas hacia el gongorismo provinieron sobre todo de los "ilustrados"; entre los detractores se hallaba Ignacio de Luzán, quien, en su Poética o reglas de la poesía, lanza un ataque contra el cordobés, que reflejaría la actitud de sus contemporáneos hacia Góngora: "se deberá también apreciar más un soneto afectuoso de Garcilaso, o de Lupercio Leonardo, o de otro cualquier poeta de buen gusto, que todos los conceptos y toda la afectación de Góngora, o de otros poetas del mismo estilo"21. A mediados de ese mismo siglo, se decía que en el "pecado culterano", como se le hacía llamar al estilo gongorino, habían incidido varios jesuitas durante su juventud. Algunos ignacianos desterrados habían hecho eco de la campaña de desprestigio; el mexicano Manuel Fabri, por ejemplo, critica a Diego José Abad, pues, "había pecado por excesivo refinamiento y ampulosidad y por los falsos ornatos de la expresión" 22 , ya que "hacia ese tiempo [los años juveniles] era seducido miserablemente por la lectura de Juan Barclay y de

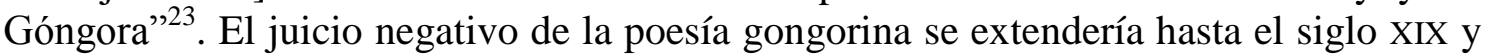
principios del XX, y pesaría al momento de evaluar la obra poética de los discípulos del cordobés, entre ellos Aguirre.

Por otra parte, el rechazo a las "Décimas" provenía de la mala reputación que tenía la sátira, por ser utilizada para denigrar a las autoridades, cuestionar y ridiculizar "las costumbres, las ceremonias, [...] las oraciones, la muerte y hasta Dios" ${ }^{\text {"24 }}$. Aunque el género fue sumamente explotado por americanos de distintos grupos culturales durante el periodo virreinal y su uso tuvo como resultado obras significativas (recuérdese a Juan del Valle y Caviedes), se le asoció frecuentemente con el gusto

\footnotetext{
${ }^{16}$ Ibíd.: 99-100.

${ }^{17}$ Véase como ejemplo Gutiérrez, 1871: 653.

${ }^{18}$ Las "Décimas" a Guayaquil y Quito, que en su momento habían causado polémica, fueron reproducidas por Pedro Fermín Cevallos en su artículo biográfico "Ecuatorianos ilustres: el padre Juan Bautista Aguirre" en Quito (1861: 122-125).

${ }^{19}$ Mera, 1868: 56.

${ }^{20}$ Ibíd.: 56-64.

${ }^{21}$ Luzán, 1956: 109.

${ }^{22}$ Ibíd.: 189.

${ }^{23}$ Ibídem.

${ }^{24}$ González, 1986: 78.
} 
ramplón y malicioso del pueblo. La actitud de León Mera hacia el tono humorístico de Aguirre respondía a estas ideas. Cabe destacar que su opinión revela más la postura de un inquisidor del Santo Oficio, que la de un crítico que atiende al contexto del autor y a los modelos literarios de la época. Este estudioso tal vez había olvidado que la poesía satírico-burlesca gozaba de gran aceptación en las academias literarias de los siglos XVII y XVIII, y, sobre todo, que era una forma para probar el ingenio y artificio del poeta de aquellos tiempos.

La copia que realizó Gutiérrez del primer manuscrito, y del que solamente había dado a conocer en el volumen de 1865 quince de sus poemas, sirvió de base para que, de manera unilateral y absolutamente autónoma, se formaran dos ediciones con la obra poética de Aguirre: Poesías y obras oratorias, editada por Gonzalo Zaldumbide en 1943 y Un olvidado poeta colonial, que preparó Emilio Carilla en Buenos Aires en 1943. La publicación casi simultánea de estas dos compilaciones daría lugar a una polémica abierta por Zaldumbide, y que años más tarde fue incorporada al estudio introductorio de Los dos primeros poetas coloniales ecuatorianos, en el apartado "VI. Addenda" de la parte dedicada a Aguirre, en el que incluso cita pormenorizada relación de sus estudios sobre este poeta barroco, sus críticas y desde luego sus pesquisas, y donde transcribe parte de su contacto epistolar con Felipe Lavalle, director de la Biblioteca del Congreso de Buenos Aires, donde fue depositado el primer manuscrito con los versos del poeta. Todo ello para demostrar su primacía en el rescate de la obra de Aguirre frente a lo hecho por Emilio Carilla ${ }^{25}$.

Complementaría lo hallado por Juan María Gutiérrez y dado a la estampa tanto por Zaldumbide como por Carilla el hallazgo que protagonizó el padre Julián Bravo en Cuenca, Ecuador, el año de 1979, es decir, a distancia mayor de un siglo, al localizar en un archivo conventual "un librito encuadernado con pasta de cuero, con adornos de oro, 87 hojas con bellos adornos a pluma" ${ }^{26}$; este segundo manuscrito, que según Francisco Javier Cevallos también parecía "ser autógrafo" como el primero, lo editó el propio Julián Bravo -"con un estudio de Ernesto Bravo"- bajo el título Nuevas poesías, en $1979^{27}$.

Por su parte, Rodríguez Castelo ha señalado, en el estudio introductorio a Letras de la Audiencia de Quito, que este segundo libro manuscrito contenía cinco poemas, de los que cuatro eran desconocidos, y agregaba:

"Dos de esos poemas son fechables, con toda certeza el uno, con harta probabilidad el otro. Y nos dejan ante los versos "juveniles" de Aguirre que el manuscrito de Guayaquil anunciaba, pero Gutiérrez no copió (esos dos poemas de los que él habla: la elegía a la muerte de Felipe V, que debió ser de 1746, y las liras, elegíacas también, al terremoto de Lima que, de acuerdo con el motivo, hay que poner en 1747). El "Rasgo épico a la llegada de la misión del padre Tomás Nieto Polo" féchase por doble referencia coincidente, una interna y otra externa. La interna es la confesión del propio poeta en la primera octava: "florecer me hizo veinte y cuatro abriles"; la externa, la data del asunto. El regreso a Quito del procurador Nieto Polo con la expedición de los misioneros cuya llegada a Guayaquil canta el "Rasgo épico"- ocurrió a comienzos de 1750. Así que al poeta lo tomó en los veinticuatro años que él dijo. El otro poema

\footnotetext{
${ }^{25}$ Zaldumbide, 1960: 371-382.

${ }^{26}$ Rodríguez, 1984: LVIII.

${ }^{27}$ Aguirre, 1999: 46.
} 
datable resulta un poco anterior, pues es elegía a la muerte del celebérrimo predicador sagrado, doctor Ignacio Chiriboga y Daza, acaecida en $1748^{\prime 28}$.

Salvo aclaración en contra, todo parece indicar que el primer manuscrito de Aguirre contenía, además de los poemas en tránsito de escritura y preparación, obras de juventud y madurez, mientras el contenido del segundo reunía obras de juventud y primera madurez, de acuerdo con la atinada datación sugerida por Rodríguez Castelo.

Sería el padre Aurelio Espinosa Pólit el encargado de establecer, en 1959, el texto definitivo de los poemas conservados en el primer manuscrito, y de acuerdo con la copia realizada por Juan María Gutiérrez y la copia que Zaldumbide solicitó a la Biblioteca del Congreso y fue realizada por el personal técnico de esta institución, en razón de que tanto en las ediciones de Carilla como en la de Zaldumbide habían sido impresas cantidad ingente de variantes y yerros de copia, debido a distintas manos y circunstancias. Asimismo, reconstruyó el corpus particular de las "Décimas" dedicadas por Aguirre a Guayaquil y Quito, a las que puso especial atención por tratarse, quizá, de la única pieza de Aguirre que durante mucho tiempo se conoció y fue varias veces reproducida en la prensa y en diversas antologías. ${ }^{29}$

Finalmente, Francisco Javier Cevallos Candau publicó en 1983, con el título Juan Bautista Aguirre y el barroco colonial, una edición con la poesía de Aguirre y el primer estudio que intenta dar una visión cabal de su mundo poético. Ahí divide su obra en religiosa, mitológica y miscelánea (dentro de esta última ubica la moral, amorosa y satírica), y analiza diversos textos atendiendo a la "cultura literaria" del autor. Quizá el mayor mérito del estudio de Cevallos sea considerar las lecturas y modelos literarios del ignaciano al momento de analizar varias composiciones poéticas, pues esto las coloca en su justa dimensión y las libera de los prejuicios de sus antiguos censores. Años más tarde, el mismo Cevallos, en su ensayo "Juan Bautista Aguirre y la poética colonial" (1999), reitera la necesidad de acercarnos a este poeta desde su contexto literario, pues:

"Aguirre cree que el texto es el resultado del dominio de la técnica y retórica, y el esfuerzo y talento del autor. Poeta barroco, despliega su arte para construir este cuidadoso rompecabezas en el que todas las piezas encajan perfectamente. El lector ideal de Aguirre tiene la clave para descifrar el poema. Esa clave incluye conocimientos de mitología, de la literatura preferida de la época, de teología básica"30.

Este conocimiento evitará hacer sobre interpretaciones o lecturas erradas de su poesía. Cevallos también indica que el crítico de Aguirre deberá analizar su obra poética considerando "la tradición culterana gongorista" a la par de la "función social", didáctica o doctrinal que pueda desprenderse de su obra poética ${ }^{31}$. El editor reúne en un solo volumen veinticuatro composiciones en verso de Aguirre y su edición es la más completa que hasta ahora se conoce de la producción poética del jesuita, aunque dista

\footnotetext{
${ }^{28}$ Rodríguez Castelo, 1984: LVIII-LIX.

${ }^{29}$ Señalaba Espinosa Pólit: "Para esta publicación íntegra he tenido la fortuna de hallar entre los papeles del Dr. César Borja Lavayen, que ahora forman parte del archivo ecuatoriano del Instituto Superior de Humanidades Clásicas de Cotocollao, una copia manuscrita en que figuran 34 décimas: 11 de Guayaquil, la de transición y 22 de Quito. Le faltan, sin embargo, 2 de las publicadas por El Iris. Completando con estas dos el manuscrito del doctor César Borja, tenemos para esta edición definitiva 36 décimas, 10 de ellas desconocidas hasta ahora" (Zaldumbide, 1960: 430).

${ }^{30}$ Cevallos Candau, 1999: 53.

${ }^{31}$ Ibíd.: 48.
} 
aún de ser la definitiva, pues carece de un estudio pormenorizado de los errores de transmisión de la obra (que incluya los poemas terminados y los fragmentos) y de la fijación de un texto base.

Los últimos años se han caracterizado por un profundo silencio respecto a la figura de Aguirre, por lo que hoy amerita una nueva reedición su poesía y, sobre todo, una edición crítica y anotada, que tome en cuenta todos los avatares que ha sufrido su obra, que detalle las características de los manuscritos de Aguirre; los cambios, enmiendas y erratas hechos por los editores del XIX y XX; que anote y aclare aquellos términos de difícil entendimiento o con un sentido particular en la poética de Aguirre; que considere la educación, lecturas y preceptivas dadas a los jesuitas, pues indudablemente de ellas bebió el autor para componer sus poemas. Se necesitan, también, más estudios que ayuden a entenderla y le restituyan su valor, el cual se ha visto empañado y desprestigiado por críticos que sólo se centran en su vena humorística o, peor aún, que hacen conjeturas sin conocer a profundidad su obra. A casi tres siglos del natalicio de Aguirre conviene empezar esta urgente tarea de crítica textual, que indudablemente arrojará nuevas luces sobre los trabajos materiales e intelectuales de los jesuitas en territorio americano.

\section{Referencias}

Aguirre, J. B. (1943). Poesías y obras oratorias. Est. preliminar Gonzalo Zaldumbide. Quito: Instituto Cultural Ecuatoriano.

(1979). Nuevas poesías. Ed. Ernesto Bravo P. Quito: Ediciones de la Biblioteca Ecuatoriana.

Carilla, E. (1943). Un olvidado poeta colonial. Buenos Aires: Imprenta de la Universidad.

Cevallos Candau, F. J. (1983). Juan Bautista Aguirre y el barroco colonial. Madrid: Edi-6.

(1999). "Juan Bautista Aguirre y la poética colonial”. En Georgina Sabat de Rivers (ed). Esta, de nuestra América pupila. Estudios de poesía colonial. Houston: Society for Reinassance and Baroque Hispanic Poetry, 43-55.

Cevallos, P. F. (1861). "Ecuatorianos ilustres: el padre Juan Bautista Aguirre". El Iris. $8,122-125$.

Espinosa Pólit, A. (1892). Antología ecuatoriana. Poetas. Quito: Imprenta de la Universidad Central del Ecuador.

González Casanova, P. (1986). La literatura perseguida en la crisis de la Colonia. México: Secretaría de Educación Pública.

Gutiérrez, J. M. (1871). "Biblioteca de escritores en verso". Revista del Río de la Plata. T. 1. Buenos Aires: Carlos Casavalle-Imprenta y Librería de Mayo.

Herrera, P. (1860). Ensayo sobre la Historia de la Literatura Ecuatoriana. Quito: Imprenta del Gobierno.

(1895). Antología de prosistas ecuatorianos. T. 1. Quito: Imprenta del Gobierno. 
Luzán, I. de (1956). Poética o reglas de la poesía. T. 1. Est. Luigi de Filippo. Barcelona: Selecciones Bibliófilas.

Mera, J. L. (1868). Ojeada histórico-crítica sobre la poesía ecuatoriana. Desde su época más remota hasta nuestros días. Quito: Imprenta de J. Pablo Sanz.

Rodríguez Castelo, H. (Ed.) (1984). Letras de la Audiencia de Quito. (Periodo jesuítico). Selección, prólogo y cronología H. Rodríguez Castelo. Caracas: Biblioteca Ayacucho.

Uriarte, J. E. de y Lecina, M. (1925). Biblioteca de escritores de la Compañía de Jesús pertenecientes a la antigua asistencia de España, desde sus orígenes hasta el año de 1773. T. 1. Madrid: sin pie de imprenta.

Zaldumbide, G. y Espinosa Pólit, A. (1960). Los dos primeros poetas coloniales ecuatorianos, siglos XVII y XVIII: Antonio de Bastidas [y] Juan Bautista Aguirre. Puebla: Editorial Cajica. 